\title{
ERRATUM
}

Chen Xiu • Michael Gerisch $\cdot$ Christiane Ilg

Klaus Henle $\cdot$ Zhiyun Ouyang

\section{Erratum to: Effects of hydrologic modifications to riparian plant communities in a large river system in northern China}

Published online: 20 May 2015

(C) The Ecological Society of Japan 2015

\section{Erratum to: Ecol Res \\ DOI 10.1007/s11284-015-1243-9}

The author would like to correct the errors in the publication of the original article. The corrected details are given below for your reading.

The sixth sentence, below the Methods section, under the subheading "Vegetation and environmental variable sampling" in the second paragraph, should read "In total, nine study sites and 36 plots were established within the riparian zone along the river. These were distributed among the three stream types, i.e., 12 plots for perennial, eight for seasonal, and 16 for dried-up."

In table 3, "\%" in "Unit/scale" column for the last row "Sand" should be deleted.

The online version of the original article can be found under doi:10.1007/s11284-015-1243-9.

C. Xiu $\cdot$ Z. Ouyang $(\bowtie)$

State Key Laboratory of Urban and Regional Ecology,

Research Center for Eco-Environmental Sciences,

Chinese Academy of Sciences, 100085 Beijing, China

E-mail: zyouyang@rcees.ac.cn

Tel.: + 861062849191

M. Gerisch

Aquatic Ecology and Centre for Water and Environmental Research, University of Duisburg-Essen, Universitätsstr. 5, 45141 Essen, Germany

C. Xiu · M. Gerisch · K. Henle

Department of Conservation Biology, UFZ-Helmholtz Centre for

Environmental Research, Permoserstr.15, 04318 Leipzig, Germany

C. Ilg

Hepia-University of Applied Science Western Switzerland,

Route de Presinge 150, 1254 Jussy, Switzerland 